\title{
UM PANORÂMA SOBRE A TRAJETÓRIA DA GEOGRAFIA ENQUANTO CIÊNCIA E DISCIPLINA ESCOLAR
}

\author{
Jardel da Silva Oliveira Junior \\ Universidade Federal Rural do Rio de Janeiro - UFRRJ \\ Programa de Pós-Graduação em Geografia, Seropédica, RJ, Brasil \\ jardeljunior21@gmail.com
}

\begin{abstract}
RESUMO
A geografia enquanto ciência e a geografia escolar são alvos de diversas discussões no que tange a pesquisadores da área. Apesar de ambas manterem relações entre si, as mesmas obedecem a objetivos distintos. Por meio de uma metodologia de pesquisa bibliográfica, o objetivo deste artigo é revisar a história da ciência geográfica através dos seus paradigmas e a história da disciplina geografia nas escolas no Brasil, para se ter o entendimento de como a geografia escolar se comporta nos dias atuais. Como resultado, pôde-se compreender que a geografia escolar atualmente resulta das diversas concepções e dicotomias que abarcou a trajetória do seu conhecimento, carregando aspectos teóricometodológicos tradicionais ao mesmo tempo em que busca uma renovação dos seus conteúdos e práticas.
\end{abstract}

Palavras-chave: Ciência Geográfica. Geografia Escolar. Paradigmas Geográficos.

\section{UNA VISIÓN GENERAL DE LA RUTA DE LA GEOGRAFÍA COMO CIENCIA Y DISCIPLINA ESCOLAR}

\begin{abstract}
RESUMEN
La geografía como ciencia y geografía escolar son el tema de varias discusiones con respecto a los investigadores en el campo. Aunque ambos tienen relaciones entre sí, tienen objetivos diferentes. A través de una metodología bibliográfica, el objetivo de este artículo es revisar la historia de la ciencia geográfica a través de sus paradigmas y la historia de la disciplina de la geografía en las escuelas de Brasil, para comprender cómo se comporta la geografía escolar en la actualidad. Como resultado, podría entenderse que la geografía escolar es actualmente el resultado de las diversas concepciones y dicotomías que abarcan la trayectoria de su conocimiento, que conlleva aspectos teórico-metodológicos tradicionales mientras busca una renovación de sus contenidos y prácticas.
\end{abstract}

Palabras clabe: Ciência Geográfica. Geografia Escolar. Paradigmas Geográficos.

\section{INTRODUÇÃO}

Engana-se quem pensa que a geografia escolar e a geografia acadêmica são necessariamente iguais. Conforme menciona Gaudio (2013), apesar de apresentar aproximações, há diferenciações no tocante a essas duas demonstrações do conhecimento geográfico: o grau de ensino e os seus fins, processos e demandas.

Enquanto a ciência geográfica se dá a partir dos questionamentos da realidade e da produção de novas categorias, a geografia escolar apresenta um conhecimento mais pronto, sem espaço para a elaboração de novas teses. Enquanto os saberes científicos tratam dos problemas que a ciência deve dar a resposta, os saberes escolares se envolvem com os resultados (LESTEGÁS, 2002a, p. 174).

Esses papéis diferenciados ocorrem também em função do próprio local de difusão desses conhecimentos. O papel da universidade é diferente do papel da escola. Em conformidade com Pontuschka (2012), a universidade tem o papel de formar o profissional de geografia, seja o geógrafo

$\begin{array}{lllll}\text { Caminhos de Geografia } & \text { Uberlândia-MG } & \text { v. 21, n. } 74 & \text { Abr/2020 } & \text { p. 178-193 Página } 178\end{array}$


ou o professor de geografia. Já a escola tem o ofício principal de preparar o estudante para o mundo atual em constante transformação.

Devido a esse fato, o conhecimento geográfico científico e escolar apresentam distinções quanto a organização de sua produção. Enquanto as elaborações científicas se demonstram por uma grande variação de documentos, já que se trata de uma discussão aberta em torno de algum fenômeno, as produções escolares costumam apresentar textos mais fechados e consolidados, já especificando para o aluno o que é importante para ele aprender (AUDIGIER, 1997 apud. LESTEGÁS, 2002b).

Nesse sentido, a geografia científica e a escolar apresentam diferenciações no que tange a sua forma e finalidade e também aproximações, por uma depender da existência da outra.

\begin{abstract}
A geografia escolar se associa à cultura escolar, a uma produção/criação própria das escolas e das práticas docentes, da organização dos sistemas de ensino, das relações e tensões entre as escolas e as sociedades. Embora tenha sua especificidade, guarda com a ciência de origem uma tensão/validação, por uma necessitar da outra, seja para manter legitimidade na própria escola, seja para manter-se (ou ser instituída) também na academia (GAUDIO, 2013, p. 44).
\end{abstract}

Portanto, esta pesquisa, de caráter bibliográfico, tem como objetivo, discutir as principais ações que se refere à trajetória dessas duas formas de conhecimento, para que se possa entender como elas se relacionam nos dias atuais, apesar de percorrerem caminhos diferenciados e obedecerem a propósitos distintos.

\title{
RESULTADOS E DISCUSSÕES
}

\section{A ciência geográfica e seus paradigmas}

A ciência geográfica, ao longo do seu percurso, sofreu inúmeras mutações em suas concepções teóricas. Até os dias atuais, a geografia abarcou diversas perspectivas de análise do espaço geográfico, onde houve (e ainda há) disputas para consolidar e disseminar as diferentes formas de se pensar o espaço, na qual é comumente denominada de paradigmas ou correntes do pensamento geográfico.

Dentro dessa perspectiva, a trajetória da ciência geográfica é calcada em dois momentos: a geografia tradicional e período de renovação da mesma, onde ela passa a integrar outros elementos em seu corpo teórico e a busca de metodologias mais condizentes com as transformações sociais que ocorrem no mundo atual.

\section{A geografia tradicional}

O conhecimento geográfico começa a caminhar para o seu processo de sistematização nos anos finais do século XVII engajado pelas expansões marítimas. Por meio de relatórios de campo e conjunto de pesquisas realizados pelos viajantes e naturalistas nesse período, foram coletadas diversas informações bases para o desenvolvimento da ciência, passando a se consolidar de fato com as obras de Alexandre Von Humboldt (1769-1859) e Karl Ritter (1779-1859) que se caracterizam como os pioneiros dos primeiros paradigmas que surgem na geografia (FIALHO, 2014).

Nesse período, devido à necessidade de se buscar novos territórios do globo, a cartografia cresce significativamente, produzindo "cartas em média e grande escala com notável riqueza de informações topográficas e geológicas", além da progressão em estudos envolvendo meteorologia e oceanografia (BERNARDES, 1982, p. 392).

A geografia desenvolvida nessa época era calcada na ideologia positivista e caracterizava a geografia como uma ciência descritiva do meio natural, ou seja, a preocupação era relatar as características do espaço físico terrestre. Nessa concepção, a ciência geográfica se pautava em um único método de análise, que era o método das ciências naturais, se igualando às demais ciências. Dessa maneira, é o positivismo, voltado para a exatidão dos fatos, que eleva a geografia à categoria de fato, e é através da geografia física, que trabalha com aspectos naturais do espaço, que a geografia se consolida em primeira instância.

Devido à influência do desenvolvimento das ciências biológicas juntamente ao das ciências sociais, a geografia passou a verificar o estudo das relações do homem com o meio. Nesse sentido, a primeira

$\begin{array}{lllll}\text { Caminhos de Geografia } & \text { Uberlândia-MG } & \text { v. 21, n. } 74 & \text { Abr/2020 } & \text { p. 178-193 Página } 179\end{array}$


corrente do pensamento geográfico foi a Escola Alemã, tendo como principal teórico Frierich Ratzel (1844-1904), pautada na concepção de que o homem é produto do meio em que vive, dando a ideia de que o ser humano tem que se adaptar às condições físicas em que está inserido e que elas vão determinar as ações progressivas humanas. Pontuschka et al. (2009, p. 41) afirma que "(...) o progresso da humanidade seria obtido com o maior uso dos recursos da humanidade, propondo mesmo que se estreitassem as relações do homem com a natureza".

Esse pensamento serviu para justificar o expansionismo e a dominação dos povos brancos ou europeus em relação às populações que viviam nos trópicos, alegando que nesses lugares não haviam condições climáticas necessárias para que aquele povo se desenvolvesse.

Se opondo a essa corrente, na França, Paul Vidal de La Blache (1845-1918) afirma que o homem tem condições de modificar o espaço físico para a sua adaptação. Nesse paradigma, o meio ambiente não é determinante para o comportamento humano.

Por outro lado, "Vidal de La Blache definiu o objeto da geografia como a relação homem-natureza, na perspectiva da paisagem" (MORAES, 1994, p. 68). O nome Possibilismo advém da ideia de o homem ter várias possibilidades de transformar o meio natural para satisfazer as suas ações. Entretanto, na Escola Francesa ainda não se considerava o homem como ser social (CORREA, 2014). A diferença da perspectiva vidaliana para a ratzeliana é na questão do relativismo diante da construção do espaço, porém, assim como a primeira corrente, também é baseada na lógica positivista de Augusto Comte.

Diante disso, pode-se dizer que La Blache foi o percursor da geografia humana, entretanto, essa era vista através da perspectiva da paisagem. Moraes (1994, pág. 27) destaca que "a geografia Vidaliana fala de população, de agrupamentos e nunca de sociedade. Fala de estabelecimentos humanos, não de relações sociais". Isto é, o ser humano era considerado apenas para discutir a natureza, desconsiderando as relações existentes entre as pessoas.

Segundo Menezes (2009), a geografia tradicional ficou marcada pelas grandes dicotomias, principalmente no que se refere à geografia humana e geografia física. Conforme exposto:

A Geografia Tradicional foi fortemente marcada pela existência de dicotomias, como a Geografia Física e Geografia Humana, Geografia Geral e Geografia Regional. Caberia a Geografia Física ocupar-se com o estudo do quadro natural e à Geografia Humana preocupava-se com a distribuição dos aspectos originados pelas atividades humanas, nesta relação dicotômica a Geografia Física obteve a imagem de ser mais consolidada que a Geografia Humana, devido ao próprio desenvolvimento das ciências naturais (MENEZES, 2009, p. 3).

Sobre o maior avanço da geografia física, Christofoletti (1985) afirma que:

Em virtude do aparato metodológico mais eficiente das ciências físicas e da esplêndida concatenação teórica elaborada por William Morris Davis, a Geografia Física rapidamente ganhou a imagem de ser a parte cientificamente mais bem consolidada e executada [...] Destituída de aparato teórico e explicativo para as atividades humanas, assim como imprecisão dos procedimentos metodológicos, a Geografia Humana sempre se debatia na procura de justificar o seu gabarito científico, e em estabelecer sua definição e finalidades como ciência (CHRISTOFOLETTI, 1985, p. 13).

A ideologia positivista denota essa concepção de que o conhecimento científico deve ser inteiramente concentrado no método das ciências naturais. Dessa forma, os estudos voltados aos aspectos físicos da natureza fazem com que a geografia se eleve à categoria de ciência diante do conhecimento.

A última corrente do pensamento geográfico do período da geografia tradicional ficou conhecida como Regionalismo. Tendo como principais fundamentadores La Blache e Richard Hartshorne (18991992), a também chamada geografia regional se caracterizava pelo estudo da diferenciação de áreas através de elementos homogêneos comuns a esses espaços. Tendo sido apropriada principalmente pela geografia britânica e americana, o método regional foi bastante desvalorizado devido a disputa ferrenha que ocorria entre os deterministas e possibilitas no início do século XX.

De caráter menos empirista do que as outras duas abordagens, essa corrente buscava em cada área a integração de diversos fenômenos que construía uma paisagem distinta (CHRISTOFOLETTI, 1985), 
tendo o geógrafo a função de descrever as características de cada região, como estrutura, vegetação, solos, clima, recursos naturais, agricultura, ocupação e distribuição da população e etc. A geografia tradicional foi um importante alicerce para construir a base da geografia como ciência que vemos nos dias atuais. Ainda que muito limitadas e passíveis de críticas consideráveis, onde muitas das discussões sobre essas concepções já foram superadas, se faz importante ter consciência que os debates sobre essas correntes trouxeram contribuições essenciais para se pensar a ciência. Nesse sentido, percebe-se que determinadas ideias e formas de condução dessas perspectivas podem ser observadas diante do espaço que nos cerca, ainda que de forma limitada.

\title{
O movimento de renovação da geografia
}

Em meados dos anos 50, a geografia dita tradicional entra em processo de crise. Os estudiosos da área percebem que as abordagens e os métodos descritivos que a ciência estava se utilizando já não estavam conseguindo explicar a dinamicidade do mundo contemporâneo. Em meio a novas necessidades, era necessário novas linguagens e novas formas de pensar o espaço. Pontuschka et al. (2009) afirma que o capitalismo mundializou o espaço geográfico e as técnicas de abordagem da geografia tradicional não eram capazes de refletir de forma abrangente a essa complexidade.

\begin{abstract}
O período entre 1950 a 1970 é marcado por intenso movimento de crítica e renovação do pensamento geográfico no mundo e no Brasil. Orientada no início para o positivismo como fundamento do discurso geográfico existente, paulatinamente a crítica descobre no processo histórico da acumulação primitiva e na abstratividade do valor que vem com ele as origens dos problemas que se busca resolver (MOREIRA, 2014, p. 9).
\end{abstract}

Sendo assim, a geografia, na busca de reformular suas teorias e trazer uma nova contextualização dos novos fenômenos geográficos que estavam surgindo, trilha caminhos dispersos, fazendo com que a ciência geográfica analise temas sobre óticas diferenciadas. Santos (2004) alega que esse movimento fez com que a geografia não obtivesse uma unidade em seu objeto de estudo. Devido ao grande número de temas a serem explorados através de perspectivas distintas, a geografia passa a ter um caráter de síntese.

Diante desse contexto, a primeira tentativa de renovação da ciência ficou conhecida como geografia pragmática ou teorética. Essa corrente buscava se apropriar da linguagem matemática para o processo de investigação científica da organização espacial e de técnicas estatísticas como metodologia para entender as dinâmicas espaciais.

A proposta desse paradigma advinha de tentar tornar a geografia "mais científica", visto que as ciências exatas sempre foram mais valorizadas diante do conhecimento científico, devido ao seu caráter de exatidão enquanto método. A geografia pragmática se apresenta como uma ferramenta de dominação. De acordo com Moraes (1994), ao exibir seu viés meramente técnico e declarar-se automaticamente como uma concepção de geografia neutra, ela se revela o oposto do que se quer demonstrar.

\begin{abstract}
O "tecnicismo" é uma versão moderna da ideologia da neutralidade científica, já discutida ao tratar-se da proposta vidaliana. Em última instância, o planejamento sempre serve para a manutenção da realidade existente, atuando no sentido de neutralizar os conflitos e facilitar a ação do Estado. Nas sociedades capitalistas, auxilia o domínio da burguesia, orientando a alocação de capital no espaço, propondo reformas, atenuando contradições ambientais e gerando informações para a expansão das relações capitalistas de produção (MORAES, 1994, p. 115-116).
\end{abstract}

Dessa maneira, a geografia pragmática, ao surgir como proposta de renovação da ciência, não exerce um papel muito distinto das ideias da geografia tradicional, pois segue a concepção errônea da neutralidade científica e não faz uma análise do espaço considerando suas totalidades. Andrade (2008, p. 21) alega que as preocupações epistemológicas ficavam abafadas em relação aos aspectos metodológicos quando diz que "prestavam grande serviço aos governos autoritários que procuravam desenvolver o crescimento econômico, sem dar importância aos custos sociais e ecológicos desse desenvolvimento".

Sposito (2004), ao elencar as características dessa corrente, afirma que nela ainda há um "domínio da descrição, com ausência da historicidade" (p. 164). Diante desse aspecto, reafirma-se que a geografia ainda segue a mesma fórmula na qual estava sendo trabalhada até então.

\begin{tabular}{|c|c|}
\hline Caminhos de Geografia & Uberlândia-MG \\
\hline
\end{tabular}


Essa corrente foi bastante criticada pelos geógrafos com tendências radicais devido ao empobrecimento que ela trouxe para a reflexão geográfica, destacando apenas a concepções meramente matemáticas e desconsiderando as relações humanas que ocorrem no espaço, que não são exatas e muito menos neutras. No Brasil, o Instituo Brasileiro de Geografia e Estatística (IBGE) foi uma das principais fundações que propagaram a ideia dessa geografia quantitativa. Em 1971, foi fundado o primeiro Boletim de Geografia Teorética, organizado por professores do Departamento de Geografia da Faculdade de Filosofia do Rio Claro, onde eram feitas análises quantitativas do espaço, buscando um maior rigor nas análises. Estas influenciadas pelas abordagens do IBGE, no Rio de Janeiro (PONTUSCKA, et al., 2009).

Corrêa (1982) apud. Sposito (2004) alega que no Brasil, entre o período de 1965 e 1985 houve uma fase de transição do conhecimento geográfico, onde a geografia passa de uma ciência vidaliana para uma ciência pragmática, voltada para questões de planejamento.

Foi no I Encontro Nacional de Geógrafos, realizado no ano de 1972 em Presidente Prudente-SP e promovido pela Associação Brasileira de Geógrafos (AGB), que ficou marcado essa disputa entre geógrafos teoréticos e tradicionais, segundo afirma Monteiro (1980). Sposito (2004) alega que nesse evento houve a tentativa ferrenha em "enterrar" a geografia tradicional através de inúmeros trabalhos que foram apresentados e que estavam embebedados sobre a perspectiva da geografia pragmática.

Em contraponto tanto as correntes da geografia tradicional quanto a geografia pragmática, surgem as correntes denominadas geografia crítica e a geografia humanista. Na geografia crítica, a preocupação é a transformação da realidade social. Os autores vão buscar romper com a neutralidade e passar a interferir na sociedade, problematizando a conjuntura social e identificando os autores que marginalizam determinados sujeitos. Fundamentada no marxismo e no materialismo histórico e dialético, essa geografia vai denunciar as mazelas que ocorrem no espaço socialmente construído de forma desigual. A partir de então, ela vai ser considerada uma geografia da ação, em oposição a uma geografia aplicada que era como a ciência geográfica estava sendo conduzida até então.

Nesse sentido, a geografia vai passar a analisar o espaço através das relações sociais que ocorrem nos espaços materiais. Sendo assim, a luta de classes aparece como a justificativa central para demonstrar as contradições existentes nesses espaços. Essa postura crítica aproximou a geografia dos movimentos sociais, principalmente no que diz respeito a garantia de direitos básicos a população, principalmente as de baixa renda, buscando uma sociedade menos desigual.

Um dos marcos referentes a essa corrente, que fez com a ciência se empenhasse cada vez mais em estabelecer e aprofundar o seu conteúdo político, é a obra de Yves Lacoste, intitulada no Brasil como "A geografia - Isso serve em primeiro lugar para fazer a guerra". Lançada em 1976, essa produção afirma que, enquanto o Estado tem uma visão totalitária do espaço, devido a sua interferência em vários lugares, as pessoas comuns obtêm uma visão parcial da realidade, limitada a realidade em que ele convive. Sendo assim, o Estado detinha um grande mecanismo de poder diante da sociedade.

Nessa obra, Lacoste (1985) afirma que existe uma geografia dos "Estados-maiores" e a geografia dos professores. A primeira seria a geografia que vai se utilizar dos conhecimentos cartográficos e de outros elementos do espaço como ferramentas para a dominação e poder. Já a segunda seria uma forma de mascarar as verdadeiras intenções da geografia - que seria a concepção da geografia dos Estados-maiores - se utilizando de discursos pedagógicos baseados nas metodologias da geografia tradicional.

Moreira (2010, p. 31) comenta sobre as nomenclaturas destacadas por Lacoste:

\begin{abstract}
Em ambas as nomenclaturas transparece a denúncia do vezo histórico da geografia de um saber sempre colado com o poder. Poder macro do Estado e poder micro das instituições capilares da ordem, que fazem da geografia uma forma de saber simples, inútil, ingênua, mas só na aparência, diz Lacoste, por tratar-se de um poderoso recurso de inculcação de ideias que convergem aqui para a legitimação do Estado e ali para a consolidação dos símbolos de representação da ordem (MOREIRA, 2010, p. 31).
\end{abstract}

A exposição de Lacoste em relação a essa teoria vai fazer com que os estudiosos da geografia comecem a repensar o papel da ciência perante a sociedade e começa um movimento para reverter essa lógica. Em relação a outros trabalhos desenvolvidos de acordo com o pensamento da geografia 
crítica, Menezes et al. (2009) faz uma síntese mostrando as principais obras que propagaram essa corrente:

\begin{abstract}
Vários são os trabalhos desenvolvidos nessa corrente, o de David Harvey intitulado Social Justice and the City, 1973, foi um marco por representar a primeira tentativa de apresentar uma síntese e um marco teórico para análise do espaço urbano. $\mathrm{Na}$ França o movimento da Geografia Radical possui Yves Lacoste como grande nome. No Brasil, muitos autores atuam nessa linha a exemplo de Milton Santos com sua obra Por Uma Geografia Nova, 1979, onde propõe uma transformação na forma de se pensar e fazer Geografia (MENEZES et al., 2009, p. 6).
\end{abstract}

Dessa forma, a geografia crítica expandia suas argumentações e consolidava sua postura diante do pensamento científico. Porém, apesar do grande enriquecimento que essa perspectiva trouxe para a análise geográfica do espaço, a geografia crítica se equivocava ao generalizar todas as realidades sobre uma ótica marxista. Como afirma Andrade (2008), a geografia tratava a doutrina marxista como algo inquestionável. Nesse sentido, havia uma deficiência no que se refere a renovação e adaptação dessa doutrina que tem uma base europeia sobre países não-europeus, "colocando-os em uma verdadeira camisa de força, caindo assim na mesma alienação em que caíram os neopositivistas" (ANDRADE, 2008, p. 22).

Devido a essa busca de um distanciamento da "geografia neutra", a geografia crítica passa a desconsiderar vários aspectos que a mesma buscava pensar e embasar seus estudos. Algumas áreas eram vistas como "inimigas" para a geografia, como a cartografia, por exemplo. Santos (2013) alega que na obra do Lacoste, a cartografia, em especial os mapas, era vista como ferramenta de "poder e opressão", tanto para os professores quanto para o Estado. Segundo Alentejano e RochaLeão (2006) os trabalhos de campo, essenciais para a consolidação da geografia como ciência, também sofreram represálias com o surgimento da corrente radical, devido ao realce conferido a teoria.

Sendo assim, a geografia crítica em seu movimento inicial tinha dificuldades de aliar as técnicas com a sua posição teórica enquanto ciência de análise espacial. Atualmente percebe-se uma maior integração entre esses elementos, onde as técnicas servem de auxílio para demonstrar e denunciar as disparidades e contrastes presentes na sociedade.

A geografia humanista vai se pautar na valorização da subjetividade e da experiência vivida do indivíduo. Baseados em trabalhos desenvolvidos principalmente por Yi-Fu Tuan, Anne Buttimer e Edward Relph, essa corrente tem a fenomenologia como base. Nessa perspectiva, os geógrafos humanistas vão mostrar a necessidade de considerar a concepção humana em relação ao espaço que vos cerca, através de suas experiências diante daquele meio, considerando que cada ser humano enxerga o mundo através de uma ótica diferenciada baseada em sua própria realidade social.

Se o espaço não significa a mesma coisa para todos, tratá-lo como se ele fosse dotado de uma representação comum, significaria uma espécie de violência contra o indivíduo e, consequentemente, as soluções fundamentadas nessa ótica seguramente não seriam aplicáveis" (SANTOS, 2004, p. 91-92).

Nessa lógica, conforme a fala de Santos, o espaço geográfico não deve ser considerado como algo estático, mas sim como um espaço plural, onde a análise deve obedecer às diversas particularidades que estão presentes no mesmo.

\title{
A história do ensino de geografia no Brasil
}

A história da geografia escolar no Brasil se deu de forma peculiar. Ao contrário do que se pode pensar, a geografia se consolida em primeira instância no espaço escolar para posteriormente surgir na academia. Foi para suprir as necessidades da escola que surgem os primeiros cursos universitários de geografia.

Dessa maneira, se faz importante ressaltar os principais aspectos da trajetória escolar da geografia, tanto em termos teóricos quanto metodológicos, para que possamos entender o comportamento dessa disciplina escolar em tempos atuais. 


\title{
O processo de consolidação da geografia escolar no Brasil
}

A geografia aparece como disciplina escolar pela primeira vez em 1937, como componente curricular do Colégio Pedro II. Devido ao fato de a instituição ser uma referência de educação básica no país, a disciplina se torna obrigatória em todos os colégios do Brasil.

\begin{abstract}
Formalmente incorporada à Escola no Brasil a partir da fundação do Colégio Pedro II (1837), a Geografia passou a ser ensinada nas escolas secundárias do país, e desde então, faz parte dos conteúdos definidos por todas as Reformas Educacionais Brasileiras, de 1889 aos dias atuais, mantendo seu "status" de matéria obrigatória. De um saber estratégico, a Geografia se tornou um saber "apropriado" pela escola, redirecionado para os alunos (SAMPAIO, 2006, p. 2685-2686).
\end{abstract}

A partir de então, a geografia adentra nas escolas do país, onde passa-se a pensar tanto na geografia escolar quanto na geografia acadêmica quase concomitantemente, já que a institucionalização da geografia na academia acontece a partir de 1930, em consequência a criação das faculdades de "história e geografia" em São Paulo, Rio de Janeiro e outras cidades, segundo o mesmo autor.

O Brasil não criou o seu próprio modelo educacional. Segundo Rocha (2014, p.16), "o ideal de ensino acabou sendo trazido do estrangeiro. Foi da França que se "transplantou" o modelo de organização escolar, bem como a forma, e não raramente os conteúdos, adotados pelas disciplinas". O autor ainda explana que no currículo francês os estudos literários eram predominantes, porém, com um grau de menor importância, também estava presente a geografia, além da história, línguas modernas e ciências físicas e naturais.

Pontuschka et al. (2009) afirmam que no início da trajetória da geografia no contexto escolar, eram utilizados livros didáticos escritos por não geógrafos e que eram baseados no que foi a ciência até metade do século XX, na Europa. A enumeração e classificação de rios, montanhas, capitais, cidades entre outros eram as características das obras da época.

A afirmação das autoras vai de encontro com a de Rocha (2014, p. 17):

\begin{abstract}
Não podemos esquecer que, durante muito tempo, o rótulo Geografia foi utilizado para designar diferentes estudos ou produtos destes estudos. Tinha ele uma conotação quase que enciclopédica, e servia, por isso mesmo, tanto para se referir ao objeto Terra quanto para também denominar os estudos de descrição e representação daquele mesmo objeto. Em consequência, saber geografia passou a significar ter domínio do maior número de conhecimentos possível sobre os territórios e seus habitantes (ROCHA, 2014, p. 17).
\end{abstract}

Dessa maneira, a geografia se comportava quase como um catálogo dos elementos presentes no espaço geográfico, sem chance para reflexões aprofundadas sobre os aspectos abordados e muito menos sem uma relação mais densa com aspectos sociais. A geografia tradicional ia ao encontro com a própria forma de se pensar a escola. Era nesse contexto em que predominava a teoria pedagógica tradicional, onde pensava-se o professor como o "mestre absoluto" detentor de todo o conhecimento e o aluno era simplesmente um ser passivo diante do processo. Sendo assim, a geografia descritiva encontra um "habitat" adequado para se consolidar.

Nessa conjuntura, a geografia servia para construir um sentido patriótico e de nacionalismo. A elaboração de mapas por parte dos alunos era fundamental para que se alimentasse um sentimento de "amor pela pátria", descartando a ideia de uma construção histórica, mas sim de uma concepção naturalizada de Estado-Nação (VESENTINI, 1985).

A descrição das riquezas naturais e humanas do Brasil eram a base dos conteúdos de geografia justamente para alimentar uma exaltação do país nos alunos. As discussões culturais e políticas eram exclusas e, seguindo os pressupostos das correntes idealizadas por La Blache, o homem não era um elemento passível de discussão acerca da sua própria vivência no espaço enquanto ser social, e sim, apenas como agente transformador da natureza (CASSAB, 2009).

Pessoa (2007, p. 39) afirma que durante todo o período imperial, a geografia se comportou dessa forma relatada, com raras exceções. Era delineada "uma geografia de caráter puramente descritiva, mnemônica, enumerativa e enciclopédica, totalmente alheia a realidade que cerca a vida do(a) aluno(a)". 
A situação do ensino da Geografia no Império ressentiu-se também dos inúmeros problemas que afetaram todo o processo de educação. Certamente de melhoras significativas nos programas estariam relacionadas com a longa série de fatos que tumultuaram a administração do ensino secundário. Os inúmeros projetos de reforma discutidos, aprovados ou não, e arquivados; as discussões de questões em torno da centralização e descentralização, os gabinetes de "passagem", tudo isso e mais uma situação constrangedora de trabalho escolar: carência de recursos, ausência de professores qualificados e baixos salários, a ponto de escolas ficarem sem mestre por não haver interessados; a disseminação de aulas particulares de preparação para os exames, a improvisação, enfim, a falta de uma definição para a escola média (ISSLER, 1973, p. 55-56 apud. PESSOA, 2007, p.39).

Ao analisar a fala de Issler, pode-se enxergar uma relação imediata com os dias atuais, onde a situação das instituições provedoras da educação básica se encontra em sua maioria em situação parecida. Nota-se que mesmo depois de quase 200 anos, as lógicas de precariedade continuam sendo as mesmas.

As mudanças no que se refere a aspectos teórico-metodológicos na geografia escolar só começam a surgir em dado momento do período republicano, mais precisamente na segunda metade do século XX. Pessoa (2007) emite que foi nesse período que começaram a manifestar embates entre professores defensores da geografia tradicional, baseada em pressupostos descritivos e professores engajados em promover uma mudança no que se referia a disciplina, tanto em questões de metodologia de ensino, quanto nos conhecimentos específicos. Fato esse também comentado por Rocha (2009, p. 86)

Para a geografia escolar brasileira, o período também adquire uma importância ímpar. Nele se deram de forma mais acentuada o conflito entre os professores de tendência conservadora que defendiam uma concepção tradicional da geografia e de seu ensino (a geografia clássica, ensinada de forma descritiva e mnemônica), e de outro lado, professores defendendo a renovação do ensino desta disciplina, não só no que diz respeito à metodologia empregada nas salas de aulas, como também no que se refere aos conteúdos (ROCHA, 2009, p. 86).

Um dos professores que se destacaram no que se refere a esse movimento de transformação da geografia que estava sendo ensinada nas escolas foi Carlos Miguel Delgado de Carvalho (18841980). Professor do Colégio Pedro II, Delgado de Carvalho foi autor de livros didáticos importantes que impulsionaram a geografia moderna para dentro do universo escolar.

Defensor inconteste da geografia moderna nas salas de aulas, este autor, ao longo de sua obra, criticou severamente a ausência de rigor conceitual e inocuidade das ideias presentes na geografia que se ensinava no Brasil. Contrapondo-se ao que era regra, Delgado de Carvalho propôs um conhecimento mais científico da geografia. Execrou a mera nomenclatura, defendendo um estudo que partisse da geografia física elementar. No seu ponto de vista, ninguém poderia de fato desenvolver um estudo sério de geografia se não tivesse como ponto de partida a fisiografia. Afirmou também que nas aulas referentes a geografia humana deveria se dar maior destaque à antropogeografia, fato que já começava a se verificar em países europeus (ROCHA, 2009, p. 88).

Nesse sentido, a geografia escolar que se conhece nos dias atuais e que está presente nos livros didáticos começa a tomar forma partir desse importante geógrafo que muito contribuiu para a disciplina.

Delgado de Carvalho em sua trajetória teceu inúmeras críticas a geografia que se preocupava com a memorização de nomenclaturas e defendeu uma geografia escolar com princípios modernos e científicos, que já vinha criando terreno na Europa. Para o professor francês, a geografia física deveria ser o ponto de partida dos estudos de geografia, porém sem deixar de lado a antropologia, que deveria ganhar mais destaque nas aulas de geografia humana (ROCHA, 2009).

Reafirmando esse quesito, Pontuschka et al. (2009) afirmam que Delgado propôs que o território brasileiro fosse estudado a partir das regiões naturais. "Não poderia haver propostas diferentes diante do contexto de influências francesas exercidas sobre a intelectualidade brasileira, nas quais os aspectos físicos eram preponderantes" (PONTUSCHKA et al. 2009, p. 48).

Delgado de Carvalho defendia que a geografia deveria se aproximar da realidade do educando. Nesse sentido, os assuntos voltados ao Brasil deveriam ser priorizados. 
A geographia pátria precisa, por conseguinte, servir de base e de ponto de partida ao estudo da physiographia e da geologia do globo. Devemos passar mais rapidamente sobre os assumptos que não têm applicações no Brasil; deixemos o estudo mais detalhado das geleiras aos estudantes suissos e o exame circumstanciado dos volcões aos japonezes e aos equatorianos. Insistamos, em compensação, sobre climatologia tropical, sobre typos de formação littoranea, recifes, etc. (CARVALHO, 1925, p. 7 apud. PESSOA, 2007, p.48).

Dessa forma, a geografia não se comportaria mais de forma estática, sem relações e pontes com outros fenômenos. O aluno conseguiria enxergar de forma mais clara a geografia ao seu redor e consequentemente o aprendizado se daria de maneira muito mais contundente e eficaz. Outro ponto que Delgado de Carvalho defendia era a questão da metodologia. Nesse caso, a geografia deveria abraçar o método comparativo.

\begin{abstract}
Este método consistia em descrever a realidade estudada de forma objetiva, empiricamente comprovada, racionalmente exata, de maneira a inviabilizar dúvidas e contradições. Para tal, a indução, análise e síntese eram elementos cruciais, pois, ao se estudar a realidade como um todo, dividir-se-ia este todo em partes, descrevendo suas características principais após criteriosa observação, estabelecer-se-iam as relações que cada parte tinha com a outra e, somar-se-iam estas várias partes para se ter a noção do todo sistematizado. Eis, em rápidas palavras, o método científico, de fundamentação positivistafuncionalista, que os geógrafos brasileiros identificavam como o único capaz de resolver os problemas da ciência e da sociedade brasileira (FERRAZ, 1995, p. 55-56 apud. ROCHA, 2009, p. 88).
\end{abstract}

Essas propostas inovadoras trazidas por Delgado de Carvalho foram alvos de resistência por parte de alguns professores. Ferraz (1995) apud. Rocha (2009) alega que o professor em questão sofreu diversas calúnias, onde foi chamado até de "estrangeiro" devido as suas novas formas de abordagens trazidas de outro continente adaptadas a realidade brasileira. Essas resistências partiam daqueles lecionadores "acomodados", que encontravam na geografia descritiva uma certa zona de conforto para o seu trabalho.

Apesar das tentativas de evolução e avanço em relação ao ensino de geografia, ainda se percebia uma geografia muito fragmentada, onde a natureza física, a sociedade e os aspectos econômicos eram visualizadas de formas segregadas, como se uma não estivesse intimamente ligada a outra no espaço geográfico. Anos depois, com a chegada da Ditadura Militar no Brasil, nos anos 1960, várias estruturas educacionais foram reformuladas. Os currículos foram revisados e transgredidos para que atendessem a forma e a intencionalidade do governo vigente.

As disciplinas de ciências humanas foram as que mais sofreram com o golpe. Justamente por serem disciplinas que analisavam o presente e o passado referente as ações humanas, elas sofreram um retrocesso e foram severamente censuradas, característica comum do regime.

Esta Geografia escolar moderna vai perdurar até os anos de 1970, quando se institui no país os estudos sociais e se verifica o surgimento de uma Geografia escolar muito conservadora, atrelada à perspectiva pedagógica tecnicista. É quando entra em declínio a circulação de livros mais conservadores como os de Aroldo de Azevedo, Mario da Veiga Cabral, e também outros que já traziam uma perspectiva mais crítica como os de Manuel Correia de Andrade e Ilton Sete. Neste período outros livros didáticos passam a ser elaborados, agora destinados, especificamente, à disciplina então instituída pelo Governo Militar (ALBUQUERQUE, 2011, p. 24).

Como mencionado pela autora, foi criado a disciplina "Estudos Sociais" onde foram aglutinadas as disciplinas de geografia e história. Nesse sentido, as disciplinas que já não ocupavam tanto tempo na grade, teve ainda mais reduzida a sua importância dentro do contexto escolar. As disciplinas passavam a ser meramente informativas, se aproximando das ciências exatas, tratando-as como ciências de verdades absolutas e perdendo a profundidade das concepções acerca do espaço e tempo.

De acordo com Resende Filho (2014), as temáticas de geografia presentes nos Estudos Sociais eram voltadas a descrição da Terra e aos fenômenos naturais, além de nomenclaturas referentes as divisões territoriais. Por esse ângulo, percebe-se uma retomada das premissas da geografia tradicional, com um viés tecnicista, onde o foco era a memorização.

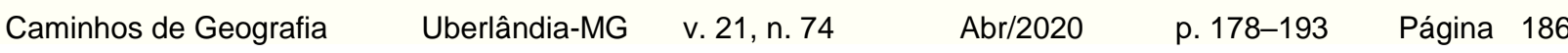




\section{O movimento de renovação da geografia nas escolas}

Perante toda conjuntura que estava sendo posta em relação ao ensino de geografia no período dos governos militares, os profissionais de postura mais crítica dessa disciplina não se acomodaram. É a partir desse período que os geógrafos começaram a incorporar novas abordagens e metodologias em suas práticas de ensino para enfrentar a retrocesso gerado pelos Estudos Sociais. Como bem evidencia Vlach (2004, p. 216-217) apud. PESSOA, 2007, p. 58)

Tal busca se intensificou no período da ditadura militar (1964-1985), quando a geografia e a história foram descaracterizadas pela lei $n^{\circ}$ 5.692/71 e diluídas nos chamados estudos sociais. As conseqüências da imposição de um regime militar conduziram, aos poucos e simultaneamente, a lutas pela redemocratização do Estado brasileiro, por uma cidadania plena, pela defesa da escola pública e pela defesa do ensino de geografia nos então primeiro (5 $5^{\underline{a}}$ a $8^{\underline{a}}$ série) e segundo graus, o que, por si só, exigia uma geografia comprometida com a realidade brasileira, indissociável da arena política mundial e de seus desafios, que também se manifestavam em escala nacional, tais como a necessidade de construção de uma sociedade que pudesse vivenciar a experiência do "ter direito a ter direitos", também do ponto de vista da questão ambiental (VLACH, 2004, p. 2016-2017 apud. PESSOA, 2007, p. 58)

O movimento de renovação da geografia nas escolas teve uma condição peculiar. Segundo Antunes (2001), o advento da geografia crítica escolar não se deu pelos professores universitários, mas sim, pelos professores do ensino básico e pelos estudantes:

Para a Geografia, o processo de renovação teve início e meio na intervenção daqueles que estavam fora da Academia - os professores de 1. e 2.. graus -, e naqueles que estavam nas Universidades e que eram tratados como espectadores os estudantes. Foi a união desses dois segmentos que garantiu o processo de renovação (ANTUNES, 2001, p. 43).

O autor realça essa questão ao referir sobre a importância do Movimento Estudantil nesse processo:

O Movimento Estudantil teve participação fundamental no processo de renovação da Geografia brasileira. O Movimento Estudantil garantiu, através da possibilidade de intervenção comprometida com um projeto de mudança e, ao mesmo tempo, descomprometida com as estruturas político-administrativas dos Departamentos formadores, as reformas curriculares e a democratização das estruturas internas da Universidade. Foram os estudantes que, literalmente, "colocaram na parede" os "donos das verdades" geográficas de outrora. A ação direta do movimento, que estava a se nutrir dos novos rumos, daqueles professores que apresentavam um novo pensar geográfico, questionando e forçando mudanças curriculares ou de natureza das políticas departamentais, acabou por detonar as transformações (Idem, p. 43).

Essa fala demonstra como é real a importância da autonomia dos alunos em sala de aula. O estudante, diferente de como se pensava as teorias pedagógicas tradicionais, é um ser pensante, que tem uma vivência e tem a capacidade de contribuir para o processo de aprendizado.

Muito dos professores que lecionam atualmente no ensino superior, atuaram anteriormente no ensino básico e começaram suas reflexões diante desse conhecimento nos anos de 1970 e 1980, quando a geografia começa a se pautar em outras conjecturas. Isto posto, muitas dessas considerações foram postuladas em dissertações, teses e livros que ajudaram a manter essas ideias vigentes no ensino de geografia (PESSOA e BRITO, 2009).

Pessoa (2007) reafirma essa questão ao destacar que foi através desse diálogo entre professores do ensino básico, engajados com essa renovação no ensino de geografia, com os professores universitários, que essa geografia crítica começou a desabrochar no universo escolar. Os docentes passaram a orientar trabalhos de monografia, dissertações e teses com vieses críticos de alunos universitários que atuavam como professores no ensino básico.

Pontuschka et al. (2009) atestam que as Secretarias de Educação de diversos estados do país produziram várias propostas curriculares em conjunto com as universidades, buscando capacitar os professores a abordarem novas formas metodológicas de acordo com esse movimento de renovação da geografia. 
Segundo Menezes (2015, p. 355-356) o movimento da geografia crítica caminhou lado a lado com a ascensão da pedagogia crítica:

\begin{abstract}
Notou-se que em paralelo ao movimento da Geografia Crítica desenvolveu-se o movimento da Pedagogia Crítica. Os pensadores de ambos defendiam pressupostos teóricos semelhantes, o que possibilitou um terreno fecundo para a discussão de uma renovação efetiva na educação, em geral, e no ensino de Geografia, em específico. Assim, a concepção de professor predominante, os cursos de formação docente e o currículo escolar foram questionados e iniciou-se uma reflexão com o intuito de construir um projeto educacional que visasse a libertação e não a alienação do sujeito e a legitimação da ordem estabelecida (MENEZES, p. 355-356).
\end{abstract}

A AGB teve um grande papel nesse processo. Conforme explicita Sposito (2004) foi no III Encontro Nacional de Geógrafos, realizado em Fortaleza, em 1978, em que teve uma maior discussão acerca de novos pensamentos em relação a geografia. Segundo o autor, esse encontro foi marcado por uma mudança na conjuntura dessas junções, dada a partir de uma nova vertente dos estudos geográficos, voltados para os ideários marxistas, e a volta de Milton Santos para o Brasil, que é um dos grandes símbolos relacionados a essa vertente geográfica.

Lacoste, que foi um dos geógrafos impulsionadores desse movimento de renovação da geografia, denuncia a forma como a geografia era trabalhada no espaço escolar, reafirmando o seu caráter de inutilidade reflexiva:

De todas as disciplinas ensinadas na escola, no secundário, a geografia é a única a parecer um saber sem aplicação prática fora do sistema de ensino. O mesmo não acontece com a história, onde se percebe, no mínimo, as ligações com a argumentação da polêmica política. A exaltação do caráter exclusivamente escolar e universitário da geografia, tendo como corolário o sentimento de sua inutilidade, é uma das mais hábeis e das mais graves mistificações que já tenha funcionado com eficácia, apesar de seu caráter muito recente, uma vez que a ocultação da geografia na qualidade de saber político e militar data apenas do fim do século XIX. É chocante constatar até que ponto se negligencia a geografia em meios que estão, no entanto, preocupados em repelir todas as mistificações e em denunciar todas as alienações. Os filósofos, que tanto escreveram para julgar a validade das ciências e que exploram hoje a arqueologia do saber, mantêm um silêncio total em relação à geografia, embora esta disciplina, mais do que qualquer outra, merecesse ter atraído suas críticas. Indiferença ou conivência inconsciente? (LACOSTE, 1985, p. 56).

As exposições do autor foram fundamentais para o processo de renovação e seus argumentos foram reafirmados e contextualizados durante o encontro de Fortaleza (SPOSITO, 2004). Pontuschka, et al. (2009) validam esse ponto ao alegarem que a AGB teve um papel importante na promoção de eventos com o objetivo de promover uma reflexão sobre o ensino e na produção de artigos científicos relacionados a temática. "A AGB nacional publicou, a partir de 1986, a revista Terra Livre, com temáticas previstas para cada volume, sendo o segundo volume, de 1987, inteiramente dedicado ao ensino de Geografia" (PONTUSCHKA, et al. 2009, p. 68).

Sendo assim, por esses encontros serem espaços de desenvolvimento e socialização do conhecimento geográfico, eles passam a contribuir de forma significativa para a disseminação de novas concepções nas escalas atuantes da geografia e na sua aplicação no contexto escolar.

O movimento de renovação da geografia no ambiente escolar está intimamente ligado a uma renovação curricular que ocorreu na década de 80 , na qual a intenção primordial era na busca por uma melhoria na qualidade do ensino. Dessa maneira, os conteúdos e maneiras de ensinar foram revisadas no que tange as diferentes disciplinas presentes no currículo das escolas. Nessa lógica, a proposta em relação a geografia era aproxima-la da realidade social, política e econômica do Brasil (PONTUSCHKA et al., 2009).

Vesentini (2004) ressalta que a geografia crítica escolar não se limita a uma renovação do conteúdo trabalhado em sala de aula, mas também por novas formas de condução para um melhor esclarecimento do objeto de análise geográfica por parte dos alunos. Conforme exposto: 
Um ensino crítico da geografia não se limita a uma renovação do conteúdo - com a incorporação de novos temas/problemas, normalmente ligados às lutas sociais: relações de gênero, ênfase na participação do cidadão/morador e não no planejamento, compreensão das desigualdades e das exclusões, dos direitos sociais (inclusive os do consumidor), da questão ambiental e das lutas ecológicas etc. Ela também implica em valorizar determinadas atitudes - combate aos preconceitos; ênfase na ética, no respeito aos direitos alheios e às diferenças; sociabilidade e inteligência emocional - e habilidades (raciocínio, aplicação/elaboração de conceitos, capacidade de observação e de crítica etc.). E para isso é fundamental uma adoção de novos procedimentos didáticos: não mais apenas ou principalmente a aula expositiva, mas, sim, estudos do meio (isto é, trabalhos fora da sala de aula), dinâmicas de grupo e trabalhos dirigidos, debates, uso de computadores (e suas redes) e outros recursos tecnológicos, preocupações com atividades interdisciplinares e com temas transversais, etc (VESENTINI, 2004, p. 228).

Dessa forma, a concepção de transformação da realidade social que está inserida em todas as reflexões acerca da geografia radical passou também a caracterizar o ensino de geografia. Norteadas por políticas pedagógicas de base marxistas, a geografia escolar reformula seus conteúdos, levando em conta a preocupação em trabalhar a criticidade do aluno (SANTOS, 2010).

Santos (2010) nos mostra uma síntese das principais modificações teóricas realizadas nos materiais didáticos nesse período:

No Brasil, por exemplo, várias coleções didáticas passaram a adotar os modos de produção e a perspectiva histórica como eixos principais de análise do conhecimento geográfico escolar (Adas, 1995). Outros autores introduziram análises espaciais tomando como base elementos da esfera socioeconômica como a ideologia e a produção e circulação de mercadorias (Pereira et al., 1993); e ainda outros ressignificaram o conceito de região à luz do conceito de desenvolvimento econômico desigual, substituindo, assim, a divisão de volumes, unidades e capítulos por continentes, por exemplo, pela regionalização do mundo a partir da divisão internacional do trabalho (Vesentini e Vlach, 1996) (SANTOS, 2010, p. 8).

Assim sendo, percebe-se o advento das ideias marxistas na geografia dentro do mundo escolar, onde eram apresentadas as análises socioespaciais através da concepção dos modos de produção, lutas de classe e as desigualdades geradas pelo sistema capitalista. Pessoa (2007) ao analisar Vesentini (2004, p. 229-230) reforça essa argumentação:

Nesse novo modelo de ensino era dada uma maior ênfase aos trabalhos planejados de campo com objetivo de desmascarar e desnudar realidades, debates extremamente participativos em que eram realizadas trocas de idéias e se alegavam razões pró ou contra temas importantes, debates em torno de novos conteúdos com temáticas voltadas ao entendimento de questões polêmicas e importantes como: reforma agrária, distribuição social da renda e subdesenvolvimento (PESSOA, 2007, p. 70).

Compreende-se então que o modelo da geografia crítica nas escolas é uma clara resposta a metodologia descritiva e mnemônica que ainda persistia em permanecer nas escolas, sendo por motivações ideológicas dos agentes dominantes, seja das condições estruturais escolares que acabavam acomodando alguns professores.

Vesentini (2010) alega que a geografia crítica percebe o espaço geográfico como espaço social, elevando a categoria como ciência social, mas que também estuda a natureza como recurso de apropriação do homem. "No ensino, ela preocupa-se com o senso crítico do educando, e não em "arrolar fatos" para que ele memorize" (VESENTINI, 2010, p. 36).

Ainda segundo o mesmo autor (2009), o ensino crítico nas escolas não deveria ser uma exclusividade da geografia por ela ter uma perspectiva denominada dessa maneira. Todas as disciplinas escolares deveriam ser críticas, onde a questão central é fazer o aluno raciocinar e pensar com uma postura crítica sobre as dinâmicas pertencentes a cada disciplina, que logicamente estão dispostas em uma realidade global.

Como foi mencionado, a geografia crítica, em seu apogeu enquanto paradigma geográfico, tentava ignorar as geotecnologias e os aspectos físicos para dar uma ênfase maior a geopolítica e outras

$\begin{array}{lllll}\text { Caminhos de Geografia } \quad \text { Uberlândia-MG } & \text { v. 21, n. } 74 \quad \text { Abr/2020 } & \text { p. 178-193 } & \text { Página } 189\end{array}$


áreas que exercem um potencial de cunho mais questionador. Entretanto, Vesentini (2009) alega que no ensino crítico de geografia nas escolas, essa separação não deve existir, mas sim haver uma integração. "O ensino crítico incentiva os alunos a raciocinarem sobre mapas e gráficos, a compararem mapas com projeções (ou perspectivas) diferentes, a interpretarem os mapas ao invés de meramente memorizá-los" (VESENTINI, 2009, p. 129, grifo do autor).

Esse processo de renovação da geografia nas escolas vem se dando de forma tardia. Devido as inúmeras falhas no sistema educacional brasileiro, como a precarização das condições de trabalho docente, por exemplo, essas mudanças vão se tornando difíceis de serem concretizadas em sua plenitude.

É importante ressaltar que, como já foi mencionado, o movimento de renovação da geografia na ciência é iniciado a partir de uma crítica a geografia teorética. Entretanto, essa geografia quantitativa não adentrou nas escolas de maneira incisiva (PONTUSCKA et al., 2009), sendo, portanto, a geografia crítica o marco concreto de uma tentativa de renovação da geografia dentro do ambiente escolar.

Um dos currículos que norteiam a geografia nas escolas são os Parâmetros Curriculares Nacionais $(\mathrm{PCN})$, o documento que dá referência à construção das matrizes curriculares nacionais. Nesse documento, os conteúdos, principalmente para o ensino fundamental são voltados para a geografia humanista de base fenomenológica. Nesse, o conceito de lugar como espaço vivido é evidenciado devido a própria história da geografia humanista, que enalteceu esse conceito em sua consolidação.

O documento afirma que nos últimos anos a produção acadêmica da geografia tem se preocupado em considerar aspectos subjetivos e singulares em relação ao vínculo do homem como sociedade e natureza. Por essa questão, a análise do espaço geográfico deve se dá de forma plural, devido a várias concepções que surgem a partir de diversas culturas na qual cada indivíduo está posto.

Conforme atestado por Rocha (2010), durante todo o documento os autores fazem críticas tanto a geografia tradicional quanto a geografia de cunho marxista. O currículo evidencia a necessidade de superação do estudo descritivo das formas da Terra e do homem, mas também faz uma crítica ao modelo de "denúncia" que a geografia crítica como ciência trouxe para o saber geográfico.

Uma geografia que não seja apenas centrada na descrição empírica da paisagem, tampouco pautada exclusivamente pela explicação política e econômica do mundo; que trabalhe tanto as relações socioculturais da paisagem como os elementos físicos e biológicos que dela fazem parte, investigando as múltiplas interações entre eles estabelecidos na construção dos lugares e territórios (BRASIL, 1998, p. 24).

Dessa forma, o documento afirma o seu posicionamento teórico de forma clara em relação a qual perspectiva da geografia o mesmo defende.

Atualmente pode-se perceber uma defesa ferrenha por parte dos pesquisadores em ensino de geografia em relação a perspectiva do conceito de lugar nos estudos geográficos na escola. Muitos propagam a ideia de sempre trabalhar os fenômenos que ocorrem no espaço geográfico primeiramente através da realidade local para posteriormente partir para uma escala global. É nessa perspectiva que a geografia humanista tenta ingressar no meio escolar, considerando o espaço vivido como o objeto fundamental para se conceber as dinâmicas socioespaciais.

A Base Nacional Comum Curricular (BNCC), documento recente que visa unificar o ensino básico em todo país, vem seguindo a proposta atual dos currículos de geografia em direcionar os estudos geográficos a questão da fenomenologia e da subjetividade do aluno. No documento se apresenta uma unidade temática que está presente em todas as séries de escolaridade do ensino fundamental chamada "O sujeito e seu lugar no mundo", onde é proposto possibilidades no que se refere a valorização do cotidiano e o reconhecimento da geografia dentro do lugar onde o estudante está inserido (BRASIL, 2019).

Entretanto, as propostas da geografia humanista para o ensino escolar ainda são muito recentes e estão presas as pesquisas acadêmicas, obtendo-se ainda uma certa resistência em relação a ação dessas investigações dentro de sala de aula, principalmente no que se refere ao material didático disponível, como o livro didático, visto que o mesmo é feito em uma escala nacional, não possibilitando exemplos dos fenômenos geográficos em escala local.

\begin{tabular}{|c|c|}
\hline Caminhos de Geografia & Uberlândia-MG \\
\hline
\end{tabular}




\section{CONSIDERAÇÕES FINAIS}

Os diversos princípios que embasaram a geografia estão, de certa forma, presentes no ensino, tanto nos currículos, quanto nos livros didáticos de variadas formas. Entretanto, é necessário ter a consciência de que a ciência geográfica e a geografia escolar, apesar de estarem interligadas em diversos pontos, apresentam trajetórias e caminhos diferentes.

A geografia tradicional, ainda que já tenha sido superada em questões teóricas e conceituais, sua metodologia ainda pode ser vista nas escolas devido aos problemas que a educação brasileira enfrenta e a falta de recursos pedagógicos que impossibilita a idealização e elaboração de metodologias mais eficazes, como já foi dito anteriormente. Em consequência a isso, a descrição de elementos geográficos, muitas vezes, se torna uma ferramenta mais "fácil" de se utilizar, ainda que se reconheça a relevância da utilização de novas formas de abordagem.

É notório que a escolha do referencial para o ensino de geografia vai depender de quem está elaborando currículos e os conteúdos a serem ministrados. Dessa maneira, o professor de geografia também é responsável pela forma de abordagem geográfica que será utilizada na escola e é ele que vai decidir qual linha de pensamento geográfico ele vai se apropriar e embasar suas aulas, influenciado pela sua formação acadêmica juntamente as suas concepções ideológicas.

Souza Neto $(2008$, p. 118) aponta que "a opção por tornar-se consciente daquilo que se ensina é uma opção política". Nessa perspectiva, refletir sobre o que e como está sendo explorada a geografia em sala de aula é uma tarefa responsável e necessária para a construção de uma geografia reflexiva dentro de sala de aula.

\section{AGRADECIMENTOS}

Agradecimentos a Coordenação de Aperfeiçoamento de Pessoal de Nível Superior - Brasil (CAPES) pelo financiamento da pesquisa.

\section{REFERÊNCIAS}

ALBUQUERQUE, M. Dois momentos na história da Geografia escolar: a Geografia clássica e as contribuições de Delgado de Carvalho. Revista Brasileira de Educação em Geografia. v. 1. n. 2. Campinas, 2011. p. 19-51.

ALENTEJANO, P. R. R.; ROCHA LEÃO, O. M. Trabalho de Campo: Uma ferramenta essencial para os geógrafos ou um instrumento banalizado? Boletim Paulista de Geografia. n. 84. 2006. p. 51-68.

ANDRADE, M. C. Geografia: Ciência da Sociedade. Recife: Edição Universitária da UFPE, 2008.

ANTUNES, C. F. Os estudantes e as transformações da Geografia brasileira. GEOGRAFARES, Vitória, n. 2, jun. 2001. p. 41-52. https://doi.org/10.7147/GEO2.1139

BERNARDES, N. O pensamento geográfico tradicional. Revista Brasileira de Geografia. Rio de Janeiro. Ano 44, n. 3. jul./set. 1982. p. 389-538.

BRASIL. MINISTÉRIO DA EDUCAÇÃO. Base Nacional Comum Curricular. Brasília (2019). DF. Disponível em <http://basenacionalcomum.mec.gov.br/\#/site/inicio> Acesso em 20/02/2020.

Parâmetros Curriculares Nacionais. Brasília: MEC/ SEF, 1998.

CASSAB, C. Geografia científica e Geografia escolar: O diálogo necessário. In: ENCONTRO DE GEOÓGRAFOS DA AMÉRICA LATINA. Anais..., Montevidéu, Uruguai: EGAL, 2009, p. 1-15.

CHRISTOFOLETTI, A. Perspectivas da Geografia. $2^{\underline{a}}$ ed. São Paulo: DEFEL,1985.

CORREA, C. Z. Objeto de Estudo da Geografia: análise do conceito segundo os professores da rede pública de ensino de Londrina-PR. 2014. Dissertação (Mestrado em Educação). Centro de Educação, Comunicação e Artes. Universidade Estadual de Londrina. $122 f$.

FIALHO, L; MACHADO, C; SALES, J. As correntes do pensamento geográfico e a geografia ensinada no ensino fundamental: objetivos, objeto de estudo e a formação dos conceitos geográficos. Educação em Foco. Minas Gerais. v. 17, n. 23. 2014. p. 203-224. 
GAUDIO, R. Geografia do Brasil: a construção de um Corpus Escolar. Geografias, Belo Horizonte, v.9, n.1. Jan/Jun. 2013. p. 40-54.

LACOSTE, Y. A Geografia - isso serve, em primeiro lugar, para fazer a guerra. São Paulo: Papirus, 1985.

LESTEGÁS, F. R. A. Concebir la geografía escolar desde una nueva perspectiva: una disciplina al servicio de la cultura escolar. Boletín de La Associación Española de Geografía, Galiza, Espanha. n. 33. 2002a. p. 173-186.

A construção do conhecimento geográfico escolar: do modelo transpositivo à consideração disciplinar da Geografia. In: CARLOS, A. F. (Org.). Novos Caminhos da Geografia. São Paulo: Contexto, 2002b. p. 13-27.

MENEZES, M. V. et al. As principais correntes do pensamento geográfico: Uma breve discussão da categoria e análise de Lugar. Centro Cientifico Conhecer, Goiânia, Enciclopédia Biosfera n.07, 2009. p. 1-10.

MENEZES, V. S. A historiografia da geografia acadêmica e escolar: uma história de encontros e desencontros. Geographia Meridionalis. Pelotas, Rio Grande do Sul. v. 1, n. 2 Jul-Dez/2015. p. 343362. https://doi.org/10.15210/gm.v1i2.6188

MONTEIRO, C. A. F. A Geografia do Brasil (1934-1977): avaliação e tendências. São Paulo: USP/IGEOG, 1980.

MORAES, A. C. R. Geografia: Pequena história crítica. 20. Ed. São Paulo: Anablume, 1994.

MOREIRA, R. O pensamento geográfico brasileiro 2: As matrizes da renovação. $2^{\text {a }}$ ed, $1^{\text {a }}$ reimpressão. - São Paulo: Contexto, 2014.

Pensar e ser em Geografia, São Paulo: Contexto, 2010.

PESSOA, R. B. Um olhar sobre a trajetória da geografia escolar no Brasil e a visão dos alunos de ensino médio sobre a geografia atual. Dissertação (Mestrado). UFPB/CCEN. - João Pessoa, PB. 2007.

PESSOA, R. B; BRITO, F. B. B. Da origem da Geografia Crítica a Geografia Crítica escolar. In: ENCONTRO NACIONAL DE PRÁTICA DE ENSINO DE GEOGRAFIA - ENPEG, 10. Anais ..., Porto Alegre: ENPEG, 2009.

PONTUSCHKA, N. A Geografia: Pesquisa e Ensino. In: CASTELLAR, S; MUNHOZ, G. Conhecimentos escolares e Caminhos metodológicos. São Paulo: Xamã, 2012.

PONTUSCHKA, N; PAGANELLI, T; CACETE, N. Para ensinar e aprender geografia. $3^{a}$ ed. - São Paulo: Cortez, 2009.

RESENDE FILHO, C. M. Livro didático de estudos sociais: um tipo de artefato de produção cultural marcado por continuidades e resistências aos ideais da Ditadura Militar (1970-1980). Dissertação (Mestrado). UFPB/CE - João Pessoa, PB, 2014. $128 \mathrm{f}$.

ROCHA. G. O. R. O Colégio Pedro II e a institucionalização da Geografia escolar no Brasil Império. Giramundo. Rio de Janeiro. v. 1. n. 1. Jan/Jun 2014. p. 15-34.

O ensino de Geografia no Brasil: as prescrições oficiais em tempos neoliberais. Revista Contrapontos. Itajai, Santa Catarina. v. 10, n. 1, jan./abr. 2010. p. 14-28.

Por uma Geografia Moderna na sala de aula: Rui Barbosa e Delgado de Carvalho e a renovação do ensino de Geografia no Brasil. Mercator - Revista de Geografia da UFC, Fortaleza, Ceará. v. 8, n. 15, 2009. p. 75-94. https://doi.org/10.4215/RM2009.0815.0007

SAMPAIO, A. C. F; VLACH, V. R. F; MELO, A. A. História da geografia escolar brasileira: Continuando a discussão. In: Anais do VI Congresso Luso-Brasileiro de história da Educação. Uberlândia, MG. 2006. p. 2683-2694.

SANTOS, C. Saberes Cartográficos. Nova Iguaçu, Agbook. 2013.

SANTOS, E. S. Geografia escolar, pensamento geográfico e processos de recontextualização. In: ENCONTRO NACIONAL DOS GEOGRÁFOS, 16. Anais.... Porto Alegre - RS. 2010. p. 1-12 
SANTOS, M. Por uma Geografia Nova: Da crítica a Geografia a uma Geografia Crítica. $6^{\mathrm{a}}$ ed. São Paulo: Editora da Universidade de São Paulo, 2004

SOUZA NETO, M. F. A aula de geografia e algumas crônicas. Campina Grande: Bagagem, 2008.

SPOSITO, E. S. Geografia e filosofia: contribuição para o ensino do pensamento geográfico. São Paulo: Editora UNESP, 2004. https://doi.org/10.7476/9788539302741

VESENTINI, J. W. Geografia Crítica e Ensino. Orientação. Instituto de Geografia - USP. n. 6. 1985. p. 53-58.

(Org.) O Ensino de Geografia no século XXI. Campinas: Papirus, 2004.

Repensando a Geografia escolar para o século XXI. São Paulo: Plêiade, 2009.

Recebido em: 18/08/2019

Aceito para publicação em: 06/03/2020 